\title{
Atletismo Escolar: possibilidades e estratégias de objetivo, conteúdo e método em aulas de Educação Física
}

\author{
Carmen Lúcia da Silva Marques * \\ Jacob Alfredo Iora **
}

\begin{abstract}
Resumo: O atletismo vem desenvolvendo-se com o objetivo clássico (sobrepujar), utilizando métodos que visam ao rendimento, desprezando a criatividade, novas formas de movimento e inserção dessas no contexto dos esportes. Este estudo caracteriza-se como descritivo, objetivando verificar o ensino do atletismo nas aulas de Educação Física, a partir das práticas curriculares da disciplina de Atletismo1. Participaram da pesquisa os professores do município de Itaara-RS. Como resultado, definiram-se categorias que traçam a realidade pedagógica da educação física na escola e elaboraram-se meios e estratégias de reformulá-la, considerando as concepções pedagógicas que se alicerçam no curso de Educação Física-Licenciatura da UFSM.
\end{abstract}

Palavras-chave: Esportes. Currículo. Atletismo Escolar. Educação Física e treinamento.

\section{INTRODUÇÃO}

Alguns autores como Kunz (1991, 1998) e Hildebrandt (1986, 2003), assim como algumas experiências ${ }^{1}$ práticas, têm demonstrado que a Educação Física escolar parece ter a obrigação de copiar o desporto de competição, típico dos clubes esportivos e que se caracteriza pelo treinamento e pela concorrência, seja nos esportes coletivos, seja nos individuais, como o atletismo. $\mathrm{O}$ fato de a Educação Física atender mais aos interesses dos alunos com talento esportivo pode-se

\footnotetext{
* Doutora em Ciência do Movimento Humano pela Universidade Federal de Santa Maria Professora do Curso de Educação Física Licenciatura da Universidade Federal de Santa Maria (UFSM). Santa Maria, RS, Brasil. E-mail: carminhahidro@yahoo.com.br

** Graduando do Curso de Educação Física Licenciatura da Universidade Federal de Santa Maria (UFSM). Santa Maria, RS, Brasil. E-mail: jacobiora@ibest.com.br

${ }^{1}$ Experiência essa atribuída para a nossa vivência como aluno do Ensino Fundamental e Médio entre outros relatos.
} 
considerar, talvez, até como uma "irresponsabilidade pedagógica e Educacional" (KUNZ,1991, p.104).

Dessa forma, a transmissão do repertório de movimentos e jogos é limitada, ficando ainda mais restrita devido à falta de espaços físicos e materiais adequados, motivação, criatividade dos professores e, ainda, devido à falta de formação continuada que poderia trazer novas formas de desenvolver as aulas. Além disso, a Educação Física escolar não tem se preocupado em desenvolver inovações que possam contribuir para a descoberta de um número cada vez maior de brincadeiras, jogos ou mesmo uma maior variabilidade e possibilidade de movimento.

Segundo Kunz (1991), em um contexto pedagógico, perspectivas de mudança realmente desejáveis, deveriam começar para a superação de deficiências como as acima citadas. Para tanto, é necessário que o professor de Educação Física reflita mais sobre suas atividades de ensino, tendo como exemplo o Atletismo, que poderá apresentar grandes possibilidades de desenvolvimento no contexto escolar, levando em conta o objetivo do conteúdo e o método de ensino junto às aulas de Educação Física.

Para Sousa, (apud KUNZ, 1998), as formas tradicionalmente conhecidas do Atletismo, como correr, saltar e arremessar, devem servir de base para as transformações didático-pedagógicas. No entanto, suas formas devem abranger múltiplos e vários campos de experiências e aprendizagens para os alunos e não apenas serem canalizadas para os modelos padronizados de realização dessas atividades.

Assim, uma transformação na modalidade esportiva Atletismo, do ponto de vista prático, apresenta algumas dificuldades. Inicialmente, não se pode ter a ideia de que isso significa a redução de um modo correto da prática. Trata-se, sim, de uma mudança de concepção, tanto de ensino como de esporte e da maneira como é relacionado com a sociedade e com o mundo em que é perpetuado.

Hildebrandt (2003) enfatiza que, na didática de ensino, as perguntas relacionadas com os conteúdos da Educação Física não podem ser respondidas separadamente de perguntas relacionadas com os

Movimento, Porto Alegre, v. 15, n. 02, p. 103-118, abril/junho de 2009. 
objetivos. Elas também não podem ser isoladas das perguntas sobre as possibilidades metodológicas de ensino, pois questões sobre os conteúdos são também questões sobre a concepção de aula de Educação Física. E, de acordo com essas respostas, as aulas podem ser construídas de outra forma.

Portanto, o ensino do conteúdo atletismo em aulas de Educação Física se concentra em poucas modalidades, geralmente corridas e saltos. Além disso, em muitas escolas, o Atletismo é desenvolvido com o objetivo clássico de sobrepujar o adversário, através de procedimentos metodológicos que visam ao rendimento, estando à margem da criatividade, da construção de novas formas de movimento e da inserção das mesmas no contexto pedagógico dos outros esportes.

Dessa forma, buscou-se verificar como é desenvolvido o Atletismo (objetivo, conteúdos e método) nas aulas de Educação Física em escolas de ensino fundamental do Município de Itaara (RS), bem como, de forma específica, diagnosticar se as modalidades do Atletismo encontram-se na grade curricular das Escolas de Ensino Fundamental de Itaara, verificar o objetivo e o método utilizados no desenvolvimento do Atletismo escolar e constatar se o atletismo, como conteúdo, é percebido e inserido nas aulas de Educação Física.

Considera-se como fundamental a importância da Educação Física escolar atribuída por Soares et al.(1992). Nessa importância, inclui-se a variabilidade dos conteúdos, a produção da cultura corporal de movimento, o resgate dos valores que privilegiem o coletivo sobre o individual e o desenvolvimento da percepção dos alunos em jogar "com" e não "contra". Dessa forma, a partir dos dados colhidos, o presente trabalho teve por objetivo provocar esclarecimento de uma situação para uma tomada de consciência pelos próprios pesquisados dos seus problemas e das condições que os geram.

\section{Metodologia}

Empregou-se, para a realização deste estudo, a metodologia qualitativa do tipo descritiva. Os sujeitos da pesquisa são professores de

Movimento, Porto Alegre, v. 15, n. 02, p. 103-118, abril/junho de 2009. 
Educação Física das escolas do município de Itaara (RS). O instrumento de pesquisa utilizado foi entrevista semiestruturada caracterizada, segundo Minayo (1993), por ser uma abordagem livre do informante sobre o tema proposto. Nesse procedimento metodológico, destaca-se a noção de entrevista em profundidade, que possibilita um diálogo intensamente correspondido entre entrevistador e informante, na qual se busca obter informes contidos na fala dos atores sociais. Nela acontece, algumas vezes, a liberação de um pensamento crítico reprimido que, muitas vezes, chega como confidência.

Assim, apresentou-se a concretização dos resultados através da técnica de análise de conteúdo e através da categorização das respostas que, como afirma Minayo (1993), significa agrupar elementos, ideias ou expressões com características comuns ou que se relacionam entre si em torno de um conceito capaz de abranger tudo isso. Assim, articulam-se conclusões, sendo estes dados concretos com um conhecimento mais amplo ou abstrato.

\section{Desenvolvimento}

\subsection{Caracterização do Atletismo Escolar}

Desde a antiguidade, caminhar, correr, saltar e lançar são movimentos naturais e, segundo alguns autores, inatos do ser humano. A criança que, desde o nascimento, executa esses movimentos, na escola, com as aulas de Educação Física, terá a oportunidade de aperfeiçoálos. Sustenta-se em Hildebrandt (2003), que o atletismo escolar, dependendo da metodologia que é utilizada em sua aplicação, pode ser o maior responsável pelo desenvolvimento das capacidades motoras anteriormente citadas, pela promoção da saúde, e pelo desenvolvimento da personalidade da criança e do organismo, contribuindo para o desenvolvimento do sistema cardiovascular e nervoso e para aperfeiçoar as qualidades físicas fundamentais.

A ação de competir, então, é determinada não só pelas regras de local e regras motoras, mas também pela regra básica do sobrepujar. Sob as condições básicas de locais e as condições motoras

Movimento, Porto Alegre, v. 15, n. 02, p. 103-118, abril/junho de 2009. 
predeterminadas, o correr, o saltar e o lançar significam percorrer uma distância o mais rápido possível; saltar o mais longe possível ou, ainda, lançar o mais longe possível. Dessa forma, para o participante, o correr implica uma diminuição do tempo, e, no saltar e no lançar, um aumento da distância a ser alcançada.

A tematização do correr, do saltar e do lançar, no sentido do sistema do Atletismo Desportivo, levado até então para as instituições escolares, compromete os participantes com os aspectos formais das experiências corporais e do movimento que o sistema orientado da competição exige. A avaliação do rendimento na corrida, no salto e no lançamento se baseia nos padrões objetivos que são fixados pelos resultados em forma de lista (por exemplo: uma hierarquização dos resultados segundo os recordes mundiais, regionais ou categoria de participação relativa à faixa etária).

Esta análise de uma forma de esporte institucionalizado, realizada, neste caso, com o Atletismo, é um exemplo para o sistema desportivo. Com isso, supõe-se que outras modalidades do esporte também são construídas segundo o sistema do esporte aqui desenvolvido. Isso pode ser afirmado porque os outros âmbitos do esporte, de forma geral, seguem também as regras básicas do sobrepujar e a da comparação objetiva.

Neste caso,

Se o rendimento for suficiente a nível do sistema ou não, os sujeitos terão experiências de como ser bem ou mal sucedidos. Assim como o bom aluno confirma a si próprio sua capacidade de rendimento pelo certificado e pela classificação exitosa, o mal denomina-se e, é denominado pelos outros de fracassado. A orientação do atletismo pelos critérios de rendimento quase objetivos tem consequências problemáticas, especialmente para os que são considerados e declarados como fracos. Para eles fica somente a possibilidade de retirar-se do sistema, no caso as aulas de Educação Física, como pessoas incapazes de correr, saltar, lançar/arremessar. (HILDEBRANDT, 2003, p. 31)

Movimento, Porto Alegre, v. 15, n. 02, p. 103-118, abril/junho de 2009. 
Hildebrandt (2003) faz com que se pense, que este tipo de redução não pode ser apoiado nas aulas de Educação Física, ou seja, o esporte não pode ser transportado desta forma para as aulas. Quando essa forma é dominante na aula (o que, na realidade, segundo o autor, é feito), a Educação Física necessita de ser modificada. Neste caso, as qualidades e as diversidades de movimento do Atletismo em relação à experimentação de materiais alternativos, de variações de lugares para seu aprendizado e, ainda, a criatividade dos alunos, avaliada através das provas tradicionais, é totalmente perdida.

\subsection{OBJetIVO, CONTEÚdO E MÉTOdO DE AULAS DE EDUCAÇÃo FÍSICA}

Em Kunz (1991), os objetivos da Educação Física escolar são descritos em três planos: o biológico, o sinestésico e o integrador. Essas três funções gerais devem ser entendidas da seguinte forma: a função biológica deve atender a formação das qualidades físicas básicas, como força, velocidade, resistência e flexibilidade; a função sinestésica ocupa-se da formação das destrezas motoras para as diferentes modalidades esportivas e a função integradora deve desenvolver a competência social através do esporte.

Porém, como o atletismo, na qualidade de conteúdo das aulas de Educação Física, pode vir a desenvolver as três funções acima citadas? Apoiados, ainda, em Kunz enfatiza-se que

$$
\begin{aligned}
& \text { [...] ensinar Atletismo nas escolas é um processo } \\
& \text { dramático, porque, com certeza, os alunos preferem } \\
& \text { "mil vezes" jogar, brincar com bola, do que saltar, } \\
& \text { arremessar ou se matar numa corrida de quatrocentos } \\
& \text { ou mil metros. (KUNZ, 1998, p.23) }
\end{aligned}
$$

A preferência por atividades jogadas não está somente na falta de ludicidade como se apresentam as chamadas "provas" do atletismo, mas, na maioria dos casos, por lembranças de uma vivência não bem sucedida pelos parâmetros normais como essas "provas" se apresentam. Assim, o medo de novos fracassos interfere no empenho de querer aprender essa modalidade esportiva.

Seguindo a consideração de autores acima citados, os conteúdos das aulas de Educação Física, no caso do atletismo, podem vir a ser

Movimento, Porto Alegre, v. 15, n. 02, p. 103-118, abril/junho de 2009. 
entendidos como mediadores para desenvolver os objetivos da Educação Física escolar, desde que os procedimentos metodológicos utilizados para construir os propósitos da aula sejam modificados. Sendo assim, encontra-se a seguir uma citação que exemplifica uma metodologia relacionada às experiências, que pode ser aplicada ao contexto dos conteúdos da Educação Física escolar para melhorar a qualidade e concretizar seus objetivos:

\begin{abstract}
Pois, o processo de aprendizagem, baseado nas experiências autênticas, não necessita de nenhuma forma de instrução, mas sim a configuração de situações que devem propiciar experiências de movimentar-se em relação à intenção educativa. Isso parece um ato revolucionário, pois estamos acostumados a levar aos alunos os movimentos "corretos", jogos definidos. Nós afirmamos que esses métodos valem somente para a formação da identidade do professor, nada mais. Pois, "o método" conforme relato de Christian, fica no próprio ser humano. (HILDEBRANDT, 2003, p. 150).
\end{abstract}

De acordo com a citação acima, pode-se utilizar uma didática que propicie situações-experiências, nas quais, por exemplo, o esporte atletismo, do qual trata-se neste texto, pode ser analisado na perspectiva de uma encenação, como no teatro, com um cenário (os campos esportivos cada vez mais presentes em propagandas comerciais), e atores (atletas) que cumprem um determinado papel (vencedores e vencidos, são, em geral, previamente conhecidos). Analisando essa encenação do esporte espetáculo e, também, o processo histórico para se chegar a essa "evolução", pode-se lançar a seguinte questão didática: Como o esporte deve/pode ser representado na escola através da Educação Física? E, ainda, o que os alunos, realmente, podem aprender com ele?

A partir dessa encenação do atletismo como espetáculo, colocase como exemplo a seguinte questão problema: corrida coletiva.

Como podemos correr trezentos metros em 58 segundos? Dividem-se os grupos de, no máximo 5 , participantes e, como geralmente acontece, os fortes acabam formando um grupo e os fracos outro. Nessa tarefa, os alunos estudam livremente as possibilidades de

Movimento, Porto Alegre, v. 15, n. 02, p. 103-118, abril/junho de 2009. 
solucionar o problema, apresentam suas soluções ao professor e ao grupo, passando, em seguida, a realizar a experiência. (KUNZ, 1998, p. 34).

E, continuando:

Quando os alunos colocam em prática a solução encontrada para o problema, é possível os seguintes resultados: o grupo dos fortes faz em torno de 56 segundos os trezentos metros, e o grupo dos fracos em 59 segundos. Nessa oportunidade o professor esclarece que ninguém encontrou a solução definitiva para o problema, uma vez que exige correr trezentos metros em 58 segundos. Caso fosse uma competição o vencedor seria o grupo dos "fracos" uma vez que estes se aproximaram mais da solução do problema. Consegue-se desconstruir, assim, as imagens excessivamente centradas na competição e na luta de concorrentes, construindo imagens de solidariedade e cooperação e, principalmente despertando a consciência crítica (KUNZ, 1998, p. 36).

O exemplo mostra, de forma clara, como o professor pode abrir novamente a redução da experiência de movimento provocada pelo sistema esportivo, com o objetivo geral de oferecer aos alunos as possibilidades de aprender a atuar de forma autônoma. E esse objetivo implica que os conteúdos não podem ser oferecidos dentro de uma forma pré-estabelecida.

Hildebrandt (2003) enfatiza que objetivo, conteúdos e método devem estar sempre interligados nas aulas de Educação Física, pois, se aplicar uma metodologia semelhante à descrita anteriormente, esse método terá função construtiva do conteúdo com a coparticipação dos alunos no processo de ensino aprendizagem, para que as experiências possam ser vivenciadas em toda, ou em quase toda, a plenitude. Isso ocorre porque o mundo do movimento não pode, nas aulas de Educação Física, ser reduzido à reprodução de modelos motores préconfigurados.

Portanto, no âmbito da Pedagogia do esporte, que debruça seus fundamentos sobre o ensino das modalidades, tem-se essa Pedagogia como uma instância crítica, que reflete as consequências das normas

Movimento, Porto Alegre, v. 15, n. 02, p. 103-118, abril/junho de 2009. 
que são predeterminadas pelo sistema do esporte. Dessa forma, é necessário desenvolver um programa totalmente diferente, que discute criticamente o conceito de esporte e abre novamente a restrição do significado comparativo de movimento para outros significados, como: expressivos comunicativos, explorativos e produtivos.

\section{DiscussõES DOS RESULTADOS}

Ao chegar nas escolas de Ensino Fundamental do Município de Itaara (RS), antes da aplicação dos instrumentos, conversou-se com os professores, explicando o objetivo do estudo. Foi um momento informal, de descontração, no qual eles podiam expressar suas dúvidas e manifestar, ou não, o desejo de serem sujeitos da pesquisa. De uma forma geral, foi possível identificar que há significativa resistência para se desenvolver aulas da Modalidade Atletismo nas escolas pesquisadas. Essa dificuldade desencadeia-se, na opinião dos professores, principalmente pela falta de condições de trabalho favoráveis (materiais e infraestrutura).

Para a concretização deste estudo, foram considerados da maior relevância as seguintes categorias para serem analisadas quantitativamente: a) objetivo, conteúdo, método e modalidade; b) concepção de espaço/tempo no ensino da modalidade;

\subsection{ObJetivo, ConteÚdo, mÉtodo e MOdALIDADE}

Em resposta a essa categoria, evidenciaram-se que as opiniões que a permeiam estão diluídas em quase todas as respostas das perguntas pré-estabelecidas.

Ao dizer das ideias da entrevista, observou-se que a atual organização da escola está situada na sua estruturação, de acordo com os objetivos sociais que intercedem e produzem limites para o desenvolvimento do trabalho pedagógico na sala de aula. O conteúdo, por sua vez, está ligado a essa forma de trabalho pedagógico. Encontrou-se, porém, a artificialidade da vida escolar com a sua separação da produção material no seguinte discurso dos atores que legitima a fragmentação do trato com o conhecimento, articulada em meio a uma gestão

Movimento, Porto Alegre, v. 15, n. 02, p. 103-118, abril/junho de 2009. 
da escola, na sua forma autoritária, que estabelece conteúdos, mas não os articula com a real prática pedagógica dos professores.

\begin{abstract}
Sobre o conteúdo do atletismo, se resume, é dado uma parte teórica e, se possível, se passa alguma na prática e às vezes não é dado nada mesmo. (PROFESSORAA)

[...] lógico que se faz as coisas adaptadas, não visando técnica, não sei se é necessário, as novas teorias dizem que a gente não tem necessidade de tanta técnica, tão trabalhando mais a parte cooperativa. (PROFESSORA B)
\end{abstract}

Na obra de Freitas (2005) "Crítica da Organização do Trabalho Pedagógico e da Didática”, encontrou-se o par dialético conteúdo/ método. Nesta obra, o autor esclarece que a objetivação da função da escola se dá no interior de seu conteúdo/método e essa relação é encontrada na interação dialética, pois não existe, por conseguinte, uma forma que não esteja embebida de conteúdo, que não organize o movimento e a atividade desse conteúdo, do mesmo modo que não existe um conteúdo que não se expresse estruturalmente em determinada forma.

Sob esta conceituação de Freitas (2005), posicionou-se no sentido de que precedentes do par dialético conteúdo/método são os objetivos, os quais interagem com a avaliação. A hipótese que apresenta-se é que o entendimento desses pares dialéticos seja a chave para se compreender e transformar a escola, pois o desenvolvimento da categoria conteúdo/método está modulado pela categoria avaliação/objetivos. Isso decorre do eixo da didática que é composto por uma relação direta entre objetivo, conteúdo e método.

Se essa interação metodológica não prescindir os objetivos, por exemplo, esses não se entrelaçam com a avaliação. Dessa forma, pode-se estar desenvolvendo o primeiro empecilho para o desenvolvimento do conteúdo, no caso aqui o atletismo. Assim, essa fragmentação do conhecimento e a ausência de trabalho como princípio educativo, são dois aspectos fundamentais que distorcem esses princípios.

Ressalta-se que esta categoria, bem como o projeto em si, tem a função de reavivar a influência mútua entre objetivo, conteúdo e

Movimento, Porto Alegre, v. 15, n. 02, p. 103-118, abril/junho de 2009. 
método bem como a proposta da Educação Física inserida no projeto político pedagógico das escolas, a qual é entendida, por alguns autores, como uma disciplina que tem uma proximidade com questões sociais e particulares dos seres humanos em seu amadurecimento. A autoorganização dos alunos, por exemplo, visa a permitir que participem da condução da aula, da escola e da sociedade, vivenciando, desde o interior da escola, formas democráticas que trazem relevância no seu discernimento como pessoa/situação/ação.

Observou-se, a partir de algumas reflexões, que, se as escolas e, em especial, a Educação Física levar em consideração os fatos descritos anteriormente, o conhecimento pode ser produzido no interior de relações sociais e, assim, quase que invariavelmente chegar à sua compreensão unânime. A socialização do saber deve ser acompanhada, dessa forma, de uma crítica sobre as próprias origens do conhecimento.

\title{
4.2 CONCEPÇÃO DE ESPAÇO-TEMPO NO ENSINO DA MODALIDADE
}

Nesta categoria, os atores apresentaram a principal causa do não desenvolvimento do atletismo no ambiente escolar, ficando isso bem explícito na seguinte fala:

Não possui nada, nem materiais, nem um espaço adequado, nem uma caixa de areia, não tem nada aqui, nem areia a escola tem, é cimento e brita. Então, é bem complicado para se trabalhar (PROFESSORA B).

E ainda:

\begin{abstract}
Como eu já te coloquei, eu acho muito importante, porque tentei fazer alguma coisa e fiquei com medo que eles fossem se machucar, nos saltos mesmo, eles saiam e diziam "ai, professora, dói muito os tornozelos (PROFESSORA C).
\end{abstract}

Segundo Oro (1984), a prática do atletismo brasileiro está apoiada sobre a Federação Internacional de Atletismo Amador (IAAF). Na mesma linha de raciocínio, observando as condições gerais para a prática do atletismo existentes no país e confrontando com os pré-requisitos dedutíveis das orientações da IAAF, não é difícil perceber que algumas disciplinas atléticas regulamentares carecem de instalações e dos equipamentos indispensáveis para serem difundidas.

Movimento, Porto Alegre, v. 15, n. 02, p. 103-118, abril/junho de 2009. 
Segundo constatações práticas e teóricas, observa-se que, para o ensino do atletismo convencional, uma minoria de clubes e escolas consegue oferecer aos seus usuários a infraestrutura necessária. Por suposto, em tais circunstâncias, torna-se impensável a suficiência de instalações e de equipamentos para o atletismo.

Como este estudo está direcionado ao desenvolvimento de possibilidades didáticas, o posicionamento é o fato de as escolas não possuírem a infraestrutura adequada, não justifica o não ensino da modalidade. Como bem se sabe, muitas dessas escolas também não possuem quadras oficiais de futsal ou de voleibol, e isso não é motivo para não ensinar esses esportes.

Entretanto, através das concepções pedagógicas construídas como curso de Educação Física Licenciatura, cabe questionar essa realidade. Não se trata de desenvolver modalidades que agridam a integridade física dos alunos, como salto em distância sem um pequeno espaço em que tenha areia para os alunos executarem a queda ou um salto em altura sem colchões, mas sim, de ir incorporando certas modalidades atléticas ao programa da Educação Física dessas escolas e tornando esse esporte atrativo e, sobretudo, fazendo com que seja o "atletismo da escola" e não o "atletismo padronizado dentro da escola".

Como os resultados do estudo estão baseados em autores que defendem uma proposta renovadora para a Educação Física escolar, entre eles, Kunz (1994), indica-se, nesta categoria, apenas uma possibilidade, que, caso fosse desenvolvida, estaria contribuindo para melhorar a competência de autonomia, na qual os alunos poderiam sentir-se responsáveis pela aprendizagem e pelos acontecimentos da aula. Essa possibilidade resume-se na problematização de situações com diferentes obstáculos. Por exemplo, barreiras podem ser aros, caixas ou, até mesmo, confecções de garrafas Pet e fita adesiva. Na fase de transcendência, podem-se trabalhar as melhores soluções para se ultrapassar mais rapidamente os obstáculos, bem como para manter um ritmo de passadas entre esses obstáculos.

Dentre as modalidades adaptáveis, estão as corridas de velocidade, com barreira e de revezamento. $\mathrm{O}$ arremesso de peso, lançamentos de martelo/disco e outros materiais podem desenvolver a

Movimento, Porto Alegre, v. 15, n. 02, p. 103-118, abril/junho de 2009. 
técnica dos mesmos. Talvez ocorram alguns questionamentos acerca de possibilidades de adaptação do martelo. Porém, utilizando, de forma criativa, por exemplo, sacolas plásticas de mercado, para ensacar bolas, ou outro material similar, para simular uma alça, cria-se um martelo didático disponível para o ensino de sua técnica.

\section{CONSIDERAÇõES FINAIS}

Importante ressaltar, sobretudo, que os professores ainda acreditam na importância da prática do atletismo junto às outras atividades já presentes nas aulas. Isso implica, porém, que as ações dos alunos não devem ficar condicionadas às pré-condições físico-esportivas como um subsistema do esporte institucionalizado. Assim, é fundamental para o professor ter o conhecimento de como problematizar ações que possibilitem o ensino e a aprendizagem do atletismo escolar. O exemplo citado do conteúdo barreiras, adaptado com caixas de papelão, denota a desconstrução das características da instituição esportiva.

É satisfatório esboçar, também, que o pensamento renovador sobre Educação Física escolar encontra-se presente nas considerações desveladas em algumas falas, embora muitas ações ainda relacionem, de forma equivocada, as possibilidades de "desconstrução do esporte" com ausência total do ensino da técnica. Entretanto, as aproximações com as propostas renovadoras da Educação Física são ponto chave para concretizar aulas que privilegiem experiências autênticas sobre todos os esportes, entre eles o atletismo. Porém, a real "concretude" deste estudo, culmina com a reflexão de que os professores carecem de uma maior interação com a tríade dialética objetivo, conteúdo e método em suas aulas, pois essa relação apresentou-se fragmentada, como descrito na obra de Freitas (2005), levando à carência do trabalho pedagógico como princípio educativo.

Concorda-se, deste modo, com Hildebrandt (2003), que a renovação da prática pedagógica nas aulas remete a uma concepção de Educação Física com diversos significados que leva em conta o objetivo com o qual o conteúdo é apresentado, bem como o método utilizado para sua apresentação.

Movimento, Porto Alegre, v. 15, n. 02, p. 103-118, abril/junho de 2009. 
Através disso, atingiu-se o objetivo, descrito em Kunz (1991), de uma Educação Física escolar em que o biológico atenda a formação das qualidades físicas básicas, a função sinestésica ocupa-se da formação das destrezas motoras para as diferentes modalidades esportivas e a função integradora, pouco presente, venha a desenvolver a competência social através do esporte.

Assim, deve-se transmitir ao contexto pesquisado, a partir dos resultados deste estudo, as possibilidades e as estratégias educacionais para o ensino do atletismo na escola - barreiras, possibilidades de lançamentos/arremessos corridas e outras modalidades adaptáveis - construídas como curso de Educação Física-Licenciatura. Além disso, ressaltar que deve-se ter bem definido o objetivo, conteúdo e método que orientam as aulas, bem como as relações imprescindíveis e devidamente fundamentadas no decorrer da produção e configuração do presente estudo.

School Athletics: possibilities and strategies of objective, content and method In Physical Education classes.

Abstract: Athletics has been developed with the classical objective (overwhelm), using methods that aim at performance, despising the creativity, new forms of movement and insertion of these sports in the context. This study is characterized as descriptive, with the purpose to identify the Athletics' education in classes of Physical Education, from the subject of Atletismo1. Professors of Physical Education, from the schools researched, participated in the analyses. The results, defined categories that draw the pedagogical reality of Physical Education at school and means and strategies of reformulated them, considering pedagogical concepts that match Physical Education Major at UFSM.

Keywords: Sports. Curriculum. School Athletics. Physical Education and Training. 
Atletismo Escolar: posibilidades y estratégias de objetivo, contenido y método en clases de Educación Física.

Resumen: El atletismo se ha desarrollado con el objetivo clásico (sobrepasar), utilizando métodos que apuntan rendimiento, despreciando creatividad, nuevas formas de movimentación e inserción de éstas en el contexto de los deportes. Este estudio se caracteriza como descriptivo, con el objetivo de verificar la enseñanza del Atletismo en clases de Educación Física basado en las prácticas curriculares de la asignatura Atletismo1. Participaron los profesores de Educación Física de las escuelas investigadas. Como resultado se definió categorías que trazan la realidad pedagógica de la Educación Física en la escuela y se elaboró medios y estratégias de reformulación de ésta, considerando concepciones pedagógicas que se cimentan en el curso de Educación Física - Licenciatura de la UFSM.

Palabras-clave: Deportes Curriculum. Atletismo escolar. Educación y Entrenamiento físico.

\section{REFERÊNCIAS}

BRACHT, Valter. Educação física e aprendizagem social. Porto Alegre: Magister, 1992.

CHIZZOTI, Antonio. Pesquisas em ciências humanas e sociais. São Paulo: Cortez, 1998.

DAOLIO, Jocimar. Da cultura do corpo. 6. ed. São Paulo: Papirus, 2001.

FREITAS, Luiz Carlos. Crítica da organização do trabalho pedagógico e da didática. 7. ed. São Paulo: Papirus, 2005.

FREIRE, Paulo. Pedagogia do oprimido. Rio de Janeiro: Paz \& Terra, 1982.

HILDEBRANDT, R.; LAGING, R. Concepções abertas no ensino da Educação Física. Rio de Janeiro: Ao Livro Técnico, 1986.

.Textos pedagógicos sobre o ensino da Educação Física. 2. ed. ljuí: Unijuí, 2003.

KUNZ, Elenor. Educação Física ensino e mudanças. ljui: Unijuí, 1991.

In: KUNZ, Elenor (Org.). Didática da Educação Física. ljuí:Unijuí, 1998.

Movimento, Porto Alegre, v. 15, n. 02, p. 103-118, abril/junho de 2009. 
MINAYO, Maria Cecília de Sousa. Pesquisa social: Teoria Método e Criatividade. 7. ed. Rio de Janeiro: Vozes,1993.

ORO, Ubirajara. Enfoques pedagógicos da iniciação ao atletismo. In: _. Antologia do atletismo: metodologia para iniciação em escolas e clubes. Rio de Janeiro: Ao Livro Técnico,1984.

SOARES, Carmem Lucia et al. Metodologia do ensino de Educação Física. São Paulo: Cortez, 1992.

Recebido em: 18.03 .2008

Aprovado em: 16.02. 2009

Movimento, Porto Alegre, v. 15, n. 02, p. 103-118, abril/junho de 2009. 